\title{
Exploração sexual comercial e Histórias de vida: um estudo a partir dos prontuários de meninas assistidas pelo Programa Social Sentinela (Florianópolis, 1990-2010)
}

\section{Commercial sexual exploitation and Life stories: a study from the files of girls assisted by the Sentinela Social Program (Florianópolis, 1990-2010)}

\author{
Camila Serafim Daminelli ${ }^{1}$
}

\section{Resumo}

Ao estudar prontuários de adolescentes assistidas pelo Programa Social Sentinela, que atende demanda de violência e exploração sexual comercial, identificamos políticas de atendimento diferenciadas: algumas voltadas ao empoderamento familiar e ao não rompimento das relações parentais; outras, cujo desligamento temporário ou mesmo permanente com a família se fez necessário. Através da investigação de um conjunto de prontuários datados entre 1990 e 2010, propomos, no âmbito da História do Tempo Presente, analisar histórias de vida de meninas que tiveram sua trajetória marcada pelo encontro com a rede de assistência social da cidade de Florianópolis. Busca-se entender quais experiências orientaram os $\mathrm{e}$ as profissionais a optar por medidas em regime aberto e em regime fechado de internação, pelo afastamento com a rede familiar ou pela adoção. A metodologia utilizada é a da Histórias de vida, instrumento interdisciplinar que permite avultar a perspectiva interseccional.

Palavras-chave: Programa Social Sentinela; Histórias de vida; Violência e exploração sexual comercial feminina; História do Tempo Presente.
\end{abstract}

\begin{abstract}
While studying files of adolescents assisted by the Sentinela Social Program, which meets the demand for violence and commercial sexual exploitation, we identified differentiated care policies: some focused on family empowerment and the non-breaking of relationships; and others, whose temporary or even permanent disconnection with the family was necessary. Through the investigation of a set of files dated between 1990 and 2010, we propose, in the context of the History of the Present Time, to analyze life histories of girls who had their trajectory marked by the encounter with the social assistance network of the city of Florianópolis. It seeks to understand which experiences guided professionals to choose measures in open and closed institutionalization, by distance from the family, or by adoption. The methodology used is that of Life stories, an interdisciplinary instrument that allows the intersectional perspective to be enhanced.
\end{abstract}

Keywords: Sentinela Social Program; Life stories; Violence and commercial sexual exploitation; History of the Present Time.

\footnotetext{
${ }^{1}$ Doutora em História pela Universidade do Estado de Santa Catarina. Professora de História do Ensino Básico, Técnico e Tecnológico junto ao Instituto Federal do Espírito Santo - IFES/Campus Aracruz. Coordenadora do Grupo de Trabalho História da Infância e da Juventude da Anpuh/Seção Santa Catarina, no binômio 2020/2022. Brasil. E-mail: camis.hst@gmail.com | https://orcid.org/0000-0003-1893-1543
} 


\section{Considerações iniciais}

Segundo os prontuários de atendimento n. 36 , Valentina ${ }^{1}$ fora assistida pelo Programa Social Sentinela durante cerca de dez anos. A documentação encontra-se organizada ao revés, a partir de 2008, quando a última anotação da assistente social foi registrada, terminando no ano de 2001, quando, após triagem, começou a ser acompanhada pelo referido programa. O caso ainda não havia sido arquivado quando da realização da pesquisa ${ }^{2}$. Em setembro de 2008, quando o caso de Valentina deixa de ser acompanhado, a adolescente está com 16 anos, sendo solicitado seu encaminhamento ao Projeto Trabalha Juventude. O parecer do último Relatório Situacional referente ao caso de Valentina conclui o seguinte:

(...) Procuramos intervir no sentido de minorar os riscos oferecidos às crianças/adolescentes pelo contexto familiar ora apresentado. Contudo, não foi possível trabalhar as questões que requer o caso, em função da falta de disponibilidade e comprometimento da genitora, a qual não se fez presente nos atendimentos, embora tenha sido notificada por diversas vezes, bem como não retornou as inúmeras tentativas de contato telefônico [grifo nosso] ${ }^{3}$.

Na outra ponta da documentação, conhecemos a razão pela qual Valentina fora inserida no Programa Social Sentinela. Uma conselheira tutelar ${ }^{4}$ redigira solicitação de atendimento ao programa por Valentina se encontrar com seus direitos à vida, à saúde e à convivência familiar, ameaçados. Sobre a razão para o enquadramento no referido programa - cuja demanda é formada por vítimas de abuso, violência e exploração sexual - lemos o seguinte: “exibicionismo perpetrado junto ao avô",5. Trata-se da primeira documentação referente à menina anexa aos prontuários de atendimento. Valentina estava com oito anos de idade.

Encaminhada ao Programa Social Sentinela através de denúncia de abuso sexual praticado pelo avô, a existência de dita relação incestuosa fora confirmada pela família da menina. No decorrer dos anos somaram-se Boletins de Ocorrência ${ }^{6}$ e mandados de intimação em função de violência sexual perpetrada pelo companheiro da mãe, em 2006, cujas vítimas eram Valentina e sua irmã. Aos 15 anos, vemos uma nova situação delinear-se: exploração sexual comercial. A adolescente estivera fazendo "programas” junto à Praça XV de Novembro, situada no centro da cidade de Florianópolis, e adjacências ${ }^{7}$. Nos meses seguintes novos casos foram relatados, tais como o de um vizinho da família que oferecia alguns trocados para ver o corpo nu da menina.

Apesar de ter sido realizada uma série de denúncias por parte dos/as assistentes sociais e conselheiros/as tutelares, advertências do juiz à genitora, medida cautelar de afastamento do 
agressor e períodos de abrigamento em Casas Lar, é possível perceber que a rede de assistência social do município optou por não retirar Valentina do convívio familiar de maneira permanente. Apesar das propaladas medidas de empoderamento familiar - promoção dos sujeitos para que conduzam com autonomia suas vidas, pelo acesso à cidadania (DEBASTIANI; BELLINI, 2007) - não verificamos um acompanhamento sistemático com a mãe e a avó de Valentina, com quem a menina coabitava e que eram suas figuras de cuidado e autoridade. Conforme se observa no último Relatório Situacional referente ao caso, o desligamento da então adolescente se reveste do caráter de desistência. A mãe, considerada negligente por não comparecer aos atendimentos e deixar os filhos "vagando pela comunidade", foi responsabilizada pelo Programa Social Sentinela por não conseguir encaminhar satisfatoriamente Valentina à normalização de suas condutas.

Os caminhos vislumbrados pelos/as assistentes sociais e pelos/as operadores/as do Direito vieram no sentido de introduzir Valentina no mundo do trabalho. Mesmo após mais de dez anos, a destituição do poder familiar ${ }^{8}$ e o abrigamento permanente ou a adoção não foram aventados como possibilidades para enfrentamento e erradicação das violências denunciadas neste caso. Por um lado, a prática da prostituição não figura nos prontuários de forma veemente como nociva à promoção dos direitos de Valentina - haja vista que a rede de assistência social sabia que esta era a fonte de rendimento das mulheres da família. Por outro, com relação ao avô, o parecer do juiz sobre o abuso sexual fora o seguinte: "julgo extinta sua punibilidade" Noutras palavras, não houve punição para o avô, ou qualquer medida cautelar para Valentina. O padrasto, perpetrador de outras violências, somente fora afastado do lar mais de um ano após realizado Boletim de Ocorrência. Neste caso houve a expedição de medida cautelar pelo juiz, porém, a duração foi breve. Alguns meses depois, o padrasto voltou a coabitar com Valentina, os irmãos e a genitora.

O relato da investigação que segue, empreendida junto aos prontuários do Programa Social Sentinela, vem no sentido de analisar as situações que pautaram a decisão de juízes, conselheiros/as tutelares e assistentes sociais no acompanhamento e encaminhamento de três meninas assistidas por exploração sexual comercial; uma grave violação aos direitos dos quais gozavam como sujeitos em condição peculiar de desenvolvimento. No espaço deste texto, cada uma das trajetórias de vida será narrada separadamente, visando se expressarem suas especificidades. Do específico ao geral, no entanto, a documentação desvela a exploração sexual comercial no período como uma prática pautada pela perspectiva de gênero, mas também avulta a presença do elemento etário e de classe social - são meninas, sobretudo, negras, em 
situação de vulnerabilidade social e carência socioemocional - razão pela qual a perspectiva interseccional se mostra de fundamental interesse como chave de leitura do fenômeno ${ }^{10}$.

Oriunda da epistemologia feminista, conforme nos recorda Helena Hirata, a perspectiva interseccional consiste na proposta de focalizar gênero, classe, etnia, religião, orientação sexual - dentre outros marcadores sociais da diferença - como conceitos transdisciplinares integrados, refutando a hierarquização dos grandes eixos de diferenciação social na estruturação das experiências (HIRATA, 2014). Elencamos justamente o termo "meninas" para designar o sujeito das experiências narradas por entender que ele integra, consubstancia o lugar que elas ocupam em termos de gênero e fase da vida - este, um marcador fundamental deste estudo. Ao mesmo tempo em que as posições sociais não são fixas, porque se inserem em relações dinâmicas, no caso das "meninas", a infância e a adolescência tanto limitam o seu lugar numa categoria de violências que só existe provisoriamente, quanto as situam numa condição que potencializa as demais vulnerabilidades sofridas.

\section{Da "situação contrária aos bons costumes" ao Programa Social Sentinela: uma História do Tempo Presente}

Sentinela é substantivo feminino na língua portuguesa que designa situação de guarda, vigia ou patrulha, geralmente utilizado com conotação policialesca. Dentre os programas sociais implementados a partir da promulgação do Estatuto da Criança e do Adolescente, o único que possui um assim chamado título fantasia é o que se incumbe da assistência e proteção à violência e exploração sexual. Os demais - Programa Liberdade Assistida, Projeto Trabalha Juventude etc. - referem-se ao objetivo da medida socioeducativa ou ao objetivo da intervenção. ${ }^{11} \mathrm{O}$ Programa Social Sentinela parece ter sido designado em referência à necessidade de patrulhar, seja no interior das famílias, seja nos subterrâneos da cidade, práticas sensíveis, de difícil trato: atividades cujo entendimento enquanto violência/violação de direitos fundamentais ainda não estava consolidado, no alvorecer dos anos 1990.

O estudo da legislação voltada aos infantojuvenis no século XX, no Brasil, demonstra apenas recentemente a emergência da noção de violência no que se refere às práticas sexuais aí incluídas as comerciais - exercidas por essa população. A primeira legislação brasileira a tutelar crianças e adolescentes - também precursora na América Latina - referência as práticas sexuais exercidas por esses sujeitos no âmbito das atividades laborais. Trata-se do Código de Menores de 1927, cujo Art. 111, da seção “Do trabalho dos menores", vetava até a maioridade 
o emprego ou cessão, pelos pais ou responsáveis, de crianças e jovens para o labor em "cafésconcerto" e "cabarets" (BRASIL, 1927).

Outros artigos do mesmo código visavam, senão a proibição, a regulamentação de adolescentes entre 12 e 18 anos em funções artísticas, teatrais e circenses, bem como de atividades que se exercessem no âmbito público (BRASIL, 1927, Arts. 112, 113 e 115). Pais ou responsáveis que submetessem menores de 18 anos de idade a atividades "contrárias à moral e aos bons costumes" poderiam ter a prole considerada abandonada e retirada do convívio familiar. Já o Art. 143, ao referir-se aos crimes e contravenções, prescreve que se um/a menor de idade viesse a sofrer algum "atentado sexual", ou se prostituir, a pena poderia ser elevada ao dobro ou ao triplo daquela a qual estaria submetido o responsável que permitisse a companhia do/a menor com gente "viciosa ou de má vida" ou a sua coabitação com prostituta ou em "casa de tolerância" (BRASIL, 1927, Arts. 126 e 130).

No referido corpo de leis, evidenciamos a tentativa do Estado brasileiro em coibir a prática do trabalho sexual infantojuvenil tendo em vista a moralidade dessa população. Isso vale também para os chamados "atentados sexuais". As noções de violência ou de exploração não estão presentes, mas, sobretudo, a de submissão das crianças e dos/as adolescentes a práticas consideradas, a partir de então, ilegais e imorais.

No âmbito das leis, passaram-se várias décadas até que a temática das práticas sexuais comerciais infantojuvenis voltasse a estar em pauta. No país, promulgou-se em 1979 um novo Código de Menores, regido pela Doutrina da Situação Irregular. Embora esse corpo de leis tenha sido considerado intermediário entre a chamada Doutrina Salvacionista - que pautou o Código de Menores de 1927 - e a Doutrina da Proteção Integral - base do Estatuto da Criança e do Adolescente (SEGUNDO, 2003) - ele acrescenta pouco com relação às atividades sexuais comerciais. Por um lado, a lei de 1979 definia em situação irregular o/a "menor em perigo moral, devido a: a) encontrar-se, de modo habitual, em ambiente contrário aos bons costumes; b) exploração em atividade contrária aos bons costumes" (BRASIL, 1979). Por outro, retirou todas as especificidades com relação ao labor infantojuvenil, sugerindo aos operadores do Direito que se orientassem por legislação específica, a Consolidação das Leis Trabalhistas (CLT). A prática nominada da prostituição desapareceu, portanto, do aparato legal que tutelou os infantojuvenis entre 1979 e 1990.

Durante a década de 1980, a influência de organizações internacionais no Brasil - tais como a Organização Internacional do Trabalho, a Anistia Internacional e o Fundo das Nações Unidas para a Infância - nos debates públicos colocaram em cena facetas da realidade 
infantojuvenil que inseriam definitivamente, no âmbito dos discursos, a noção de sujeitos de direitos $^{12}$. No Brasil foi através da discussão pública de uma série de violações - como os chamados "esquadrões da morte"13, as torturas nas unidades de internação para os/as adolescentes infratores/as e a emergência, na mídia impressa, de denúncias sobre o circuito de meninas escravizadas sexualmente - que a Doutrina da Proteção Integral foi gestada. De acordo com esta, os infantojuvenis são sujeitos de direito prioritário, sendo dever do Estado, da família e da sociedade em geral zelar pelo seu desenvolvimento físico e mental e para que prevaleça o princípio do melhor interesse da criança e do adolescente sob os demais.

O contexto da virada da década de 1980 e início dos anos 1990 é considerado progressista em termos de proteção infantojuvenil. O que se designa hoje Sistema de Garantia de Direitos tem como marcos legais fundantes a Constituição de 1988 e a promulgação do Estatuto da Criança e do Adolescente, dois anos depois. No entanto, não passa despercebido que a criminalização da prostituição infantojuvenil tenha sido incorporada à letra desta lei somente no ano 2000, por meio do Art. 244-A. O referido artigo possui a seguinte redação: "Submeter criança ou adolescente, como tais definidos no caput $2^{\circ}$ desta lei, à prostituição ou à exploração sexual: Pena - reclusão de quatro a dez anos, e multa" (BRASIL, 1990, incluído pela Lei 9.975, de 26 de junho de 2000). Incutem na referida pena: a família da criança/adolescente em situação de exploração sexual; a demanda que requisita o labor sexual infantojuvenil e; os estabelecimentos que "empreguem" menores de idade em atividades sexuais. A relevância dessa normativa está em penalizar, pela primeira vez em termos legais, os usuários das práticas sexuais comerciais infantojuvenis, e não apenas aqueles que submetem a criança ou o/a adolescente, ou seja, que venham a ter ganhos econômicos com a prática. De acordo com o inciso $2^{\circ}$ do mesmo artigo, "constitui efeito obrigatório da condenação [além de citação pessoal] a cassação da licença de localização e de funcionamento do estabelecimento" em que se evidencie a prática da exploração sexual comercial (BRASIL, 1990).

Gestada lentamente ao longo do século XX, vê-se a prostituição infantojuvenil deslocando-se da perspectiva da corrupção moral do/a infantojuvenil que a pratica para a noção da violação, pelo corpo social como um todo, dos direitos da criança e do/a adolescente. Prova do abismo que se abriu entre o exercício da prostituição entre adultos e infantojuvenis no âmbito dos direitos é que, para os primeiros, vê-se no tempo presente a luta pela profissionalização e pela erradicação dos estigmas, enquanto para os últimos, o termo foi substituído. Segundo Eva Faleiros (2000), no que tange às práticas sexuais inseridas em relações mercadológicas ou com percepção de ganhos econômicos, agências e instâncias de promoção de direitos vêm sugerindo 
desde meados dos anos 1990 a substituição do termo "prostituição infantojuvenil" para “exploração sexual comercial".

Segundo a classificação do Instituto Iberoamericano del Niño, por exploração sexual comercial entende-se quatro gamas de atividades: a prostituição, o turismo sexual, a pornografia e o tráfico para fins sexuais (LIBÓRIO, 2005). Conforme já mencionado, o entendimento do exercício da prostituição como violação dos direitos da criança e do/a adolescente se pauta na noção de "exploração" mesmo que as atividades não sejam praticadas com coerção física ou psicológica.

De acordo com o Código Penal vigente nos marcos temporais dessa pesquisa, estavam vetadas práticas sexuais exercidas com menores de 18 anos, qualificando-se crime de corrupção de menores, independente do seu consentimento ${ }^{14}$. Em relação ao Estatuto, à já mencionada alteração da letra da lei no ano 2000 somou-se no ano de 2009 o Art. 244-B, o qual imputava pena a quem "corromper ou facilitar a corrupção de menor de 18 anos, com ele cometendo infração penal ou induzindo a praticá-la” (BRASIL, 1990, incluído pela Lei 12.015, de 07 de agosto de 2009). No período em tela, no entanto, antes destas alterações, a redação do Estatuto relacionada às práticas sexuais prescindia de termos como conjunção carnal, corrupção de menores, estupro, exploração ou violência sexual ${ }^{15}$. "Abuso sexual” figura uma única vez na letra da lei original do Estatuto, no Título IV, Art. 130, referente às medidas pertinentes aos pais ou responsáveis (BRASIL, 1990).

Segundo a assistente social Mariana Garcez Coutinho, desde a última década do século XX os profissionais do campo da assistência social têm se preocupado com a criação de programas específicos para atender a demanda de cada espécie de violência (COUTINHO, 2008). Na cidade de Florianópolis, de onde advém a documentação analisada nesse estudo, desde 1997 há programas piloto de acompanhamento de crianças e adolescentes vítimas de violência e exploração sexual. No ano 2000, criou-se um projeto mais complexo do que os anteriores, uma vez que atendia especificamente a demanda de meninos e meninas em situação de violência e exploração sexual. O Programa de Erradicação da Violência e Exploração Sexual (PEVES), propunha um conjunto de ações especializadas de enfrentamento ao fenômeno na capital catarinense, sendo substituído pelo Programa Social Sentinela em 2001, seguindo as deliberações do Conselho Nacional dos Direitos da Criança e do Adolescente (CONANDA) para que os programas sociais, embora de operacionalização a nível municipal, seguissem referência nacional (DAMINELLI, 2010). 
No período analisado, partia-se de denúncias realizadas pelo telefone - através de uma linha então conhecida como SOS Criança - para que o Conselho Tutelar realizasse a sua apuração. Uma vez confirmada a necessidade de intervenção, a família era encaminhada à triagem e, em seguida, a um dos programas específicos administrados pelo governo municipal. Foi, portanto, através de um telefonema que a vida de Valentina e de tantas outras crianças e adolescentes se encontraram com a rede de proteção e assistência de Florianópolis.

A tessitura histórica empreendida a partir dos prontuários sociais pertence aos domínios da História do Tempo Presente, campo historiográfico cujos limites não estão situados em marcos temporais definidos. De acordo com Márcia Menendes Motta, objeto e historiador/a do tempo presente compartilham uma mesma temporalidade, situação da qual emergem especificidades teórico-metodológicas ainda pouco consolidadas pelo saber histórico (MOTTA, 2012). Entre elas está a presença de um objeto-testemunha-personagem, cuja experiência vivida instiga e possibilita o estudo de processos ainda em curso. A apreensão de uma história em movimento, cujo desfecho é - como nos casos aqui estudados - desconhecido, depende tanto do conhecimento do/a historiador/a acerca do tema quanto de sua capacidade de realizar prognósticos. Nas temáticas aqui abordadas está em jogo, para o/a historiador/a do tempo presente, a possibilidade de contribuir para o aprimoramento das políticas sociais vigentes.

\section{Prontuários e Histórias de vida}

Quando Mariana ingressou no Programa Social Sentinela, no ano de 2004, aos oito anos, sua família já era assistida pela rede de assistência social da cidade de Florianópolis em razão da situação de carência socioeconômica em que vivia. A família recebia cestas básicas e vales transporte do governo municipal, através do Programa de Erradicação do Trabalho Infantil (PETI), além de roupas arrecadadas pelos profissionais da escola em que as crianças frequentavam. As assistentes sociais relataram, no mesmo ano, que Mariana e o irmão mais velho compareciam ao colégio em más condições de higiene, daí decorrentes alguns problemas de afetividade no ambiente escolar. Com relação ao encaminhamento da família ao Sentinela, o diagnóstico realizado dizia o seguinte: "Atos libidinosos sem violência física"16.

Alguns meses após o parecer acima mencionado, Mariana e a irmã mais nova, a qual se desconhece a idade à época, foram encaminhadas judicialmente a um abrigo temporário. O pai, Paulo, havia sido preso em 30 de junho de 2004. O relato das assistentes sociais envolvidas no caso afirmava que Paulo temia que os presos descobrissem o motivo da sua detenção. Dilcéia, 
mãe de Mariana e esposa de Paulo, sentia-se culpada pela prisão do companheiro. Com relação à violência sofrida pela menina, os prontuários citam a fala de Paulinho, primogênito do casal, que "viu o pai chupando as coisas de Mariana"17. Um Relatório Situacional ${ }^{18}$ descreveu os outrora referidos "atos libidinosos" da seguinte maneira:

Houve também a denúncia de que Paulo teria abusado sexualmente de sua filha Mariana. Uma irmã de Dilcéia teria alertado que toda vez que esta não estava em casa, o genitor fechava a casa e ia dormir com Mariana na mesma cama. Paulinho também colocou que o pai mostrava suas revistas pornográficas para ela e que quando a mãe saía de casa o pai tirava a roupa, deitava sobre Mariana e a beijava no rosto. Mariana confirmou que o pai lhe mostrava as revistas, e também que tirava sua calcinha, passava a mão nela e deitava pelado ao seu lado ${ }^{19}$.

O histórico do atendimento da menina e sua família envolvera, cerca de um ano após seu ingresso no Programa Social Sentinela, inúmeras denúncias além das violências sexuais as quais Mariana vinha sendo submetida: agressão física por parte de Paulo, perpetrada em Dilcéia; "mendicância" pendular desta; uso de drogas, masturbação e "exibicionismo" em frente à prole, por parte de Paulo; situação de rua experienciada por Mariana e Paulinho. Paulo esteve preso durante sete meses, quando em dezembro de 2004 lê-se que, voltando a coabitar com Dilcéia e os dois filhos - com exceção de Mariana, que permanecia abrigada em uma Casa Lar - os/as conselheiros/as tutelares advertiram sob a perda do poder familiar se no período de três meses não houvesse alterações no comportamento dos genitores.

$\mathrm{Na}$ oportunidade acima descrita, Mariana afirmou pretender ficar abrigada "até os 19 anos" e redigiu uma carta destinada ao pai, anexada aos prontuários, em que afirma não ter gostado do que o pai lhe fizera e pedia que não mais o fizesse ${ }^{20}$. Apesar do afeto expresso na carta, Mariana comunicou aos assistentes sociais que preferia o abrigo à residência familiar, pois enquanto neste habitava o genitor, naquele havia comida e ela podia dormir e brincar. Não observamos, de parte da rede de proteção, tratativas no sentido de que Mariana seguisse coabitando com sua mãe e irmãos. Para o seu caso, a "solução" parece ter sido afastá-la do ambiente em que convivia com seu agressor e, na falta deste, com sua mãe, que a submetia a situações consideradas inadequadas, a exemplo da mendicância. A mãe, por sua vez, não parece ter sido objeto de nenhuma medida socioassistencial que prezasse pela alteração das suas condutas.

Em meados de 2007, o único filho a coabitar com os genitores era Paulinho. Os pais tiveram suspenso o poder familiar nos primeiros meses de 2006. Mariana seguiu abrigada, aparentemente de forma ininterrupta, enquanto Júlia e Micael - o caçula, que nasceu após a 
inserção da família na rede de proteção social - haviam sido adotados. As últimas inserções realizadas no prontuário de Mariana relatam a tristeza da menina pela separação dos irmãos que foram adotados, além de reiteradas fugas que empreendia da instituição de abrigamento, com destino incerto $^{21}$. Na leitura dos prontuários não ficam evidenciadas tentativas de manutenção dos vínculos entre Mariana e seus irmãos, à exemplo do incentivo à adoção, ou tutela do grupo de irmãos pela mesma família, como preconiza o Art. 28 do Estatuto da Criança e do Adolescente (BRASIL, 1990).

Mariana passou abrigada seu aniversário de 11 anos. Seu rendimento escolar era baixo e possuía personalidade agressiva, de acordo com pareceres dos/as assistentes sociais. O médico que acompanhava o caso, por sua vez, redigiu o seguinte parecer: "se esta paciente fosse mais velha, teria dado à mesma o diagnóstico de Borderline, que se encontra entre a "normalidade" (neurose) e a Psicose", e finaliza com a proposta de "aumentar a dosagem dos remédios" como solução para a instabilidade da menina ${ }^{22}$. Desconhecemos se o diagnóstico fora compreendido pela rede de proteção, que lidava e convivia diariamente com Mariana. De qualquer forma, chama atenção que o tratamento sugerido pelo médico fora estritamente medicamentoso, ainda que conhecesse a amplitude das violências sofridas por Mariana.

Os prontuários de atendimento gestados no dia a dia do trabalho assistencial se pretendem um compêndio de informações presentes e pretéritas acerca das experiências vividas pelos sujeitos em assistência. Essa documentação, vasta e abundante em termos qualitativos, permite ao pesquisador/a ter acesso aos diferentes discursos que se ocuparam da vida da criança e do/a adolescente: o discurso médico, do direito, da psicologia e da assistência social. No caso de Mariana, foi possível encontrar referências a falas diretas da menina e do irmão, Paulinho, o que representa uma especificidade. Na documentação relativa à Valentina, por exemplo, sua fala apareceu predominantemente de forma indireta, mesmo tendo sido assistida durante mais tempo do que Mariana. Com relação aos personagens das histórias de vida que os prontuários possibilitam narrar, esses são igualmente múltiplos: genitores, familiares, vizinhos/as, policiais, profissionais da rede de promoção social, além das crianças e dos/as adolescentes, que estão no centro da trama, embora nem sempre configurem como protagonistas.

Em termos metodológicos, a utilização de documentos oriundos de instituições médicas, prisionais e mais atualmente, dos programas sociais, data da segunda metade do século XX. Em meados da década de 1970, na esteira da História da Loucura de Michel Foucault, deu-se no Brasil a emergência de uma produção voltada ao estudo de eventos até então tidos como atemporais, como o corpo, a loucura, a medicina, a morte e a infância. Segundo Venâncio e 
Cassillas (2010), essa nova abordagem das atividades humanas, que se desenvolve às margens da historiografia, era respaldada por documentação pioneira: diagnósticos médicos, prontuários de atendimento, processos de internamento etc. Mesmo entre si, esses documentos - gestados para informar, categorizar e dar respaldo a decisões médicas e judiciais - apresentam significativas diferenças. De acordo com a pesquisadora Zelinda Rosa Scotti (2010), que atua no campo da História da Psiquiatria, cada prontuário ou ficha de internamento tem sua especificidade de acordo com a finalidade e a datação, cabendo ao investigador/a a elaboração de uma técnica para a coleta de dados. Em outras palavras, enquanto há conjuntos de prontuários pobres em termos qualitativos, os quais há que fazer falar no exercício de cruzamento de dados - quantitativos -, há aqueles que, vastamente descritivos, permitem maiores possibilidades narrativas, como por exemplo, a reconstrução de histórias de vida.

No caso dos prontuários tecidos nos atendimentos sociais, esses se diferenciam dos Processos Judiciais, Laudos Periciais e dos Diagnósticos Médicos, por exemplo, uma vez que os relatos não foram redigidos para serem lidos por quaisquer profissionais além daqueles que prestam atendimento cotidiano. Costumavam ser construídos até meados da década de 2000 ao que tudo indica, a prática permanece nos dias atuais - para armazenar informações, com o maior detalhamento possível, sobre quaisquer contatos, atendimentos, encaminhamentos ou alterações na relação Estado-família-indivíduo visando, dentre outras coisas, que outros agentes de proteção e promoção social possam manter-se atualizados acerca da situação de cada caso.

Parece relevante, dada a especificidade das fontes documentais com as quais se trabalha, apresentar os documentos que compõem os prontuários de atendimento do Programa Social Sentinela: 1) detalhamento dos atendimentos prestados pelos/as assistentes sociais; 2) os Relatórios Situacionais, que consistem em uma síntese da situação atual do sujeito em atendimento, elaborados pelos/as assistentes sociais e destinados aos juízes da Vara da Infância e da Juventude responsáveis por cada caso; 3) Boletins de Ocorrência anexados, que são a versão policial das denúncias realizadas via programas sociais; 4) documentação oficial própria construída pelos/as conselheiros tutelares, destinada aos juízes, assistentes ou a outros personagens envolvidos; 5) produções realizadas pelas crianças e pelos/as adolescentes durante as atividades pedagógicas; e, 6) lista ou tabela com os valores econômicos fornecidos às famílias semanal ou mensalmente.

Uma vez situada e contextualizada a fonte documental desta narrativa, importa também que se esclareça o que significa incorporar o instrumento interdisciplinar das Histórias de vida neste estudo. Conforme destaca Luísa Magalhães Nogueira et al. (2017), produzir relatos 
biográficos por si só não significa operar com as Histórias de vida enquanto ferramenta de investigação, já que ela não pode prescindir da escuta, de reiteradas entrevistas não diretivas, e da coparticipação do sujeito que narra sua história na construção do conhecimento produzido pelo/a pesquisador/a. Estes são alguns dos pilares nos quais vêm se construindo o instrumento, ou a metodologia das Histórias de vida desde a sua emergência nos anos 1920 e 1930, junto à chamada Escola de Chicago. Entretanto, consideramos que o método se pauta, também de forma basilar, na exposição de um relato de vida único, mas cuja conexão com outros se sustenta na história social e no universo simbólico que partilham, permitindo que uma biografia ímpar se torne ferramenta de historicidade. A narrativa de uma biografia possibilita - ainda que não venha a ser construída em conjunto com o sujeito dessa experiência - inserir na centralidade da tessitura histórica uma existência ordinária, o que se reveste de maior importância se tratando de sujeitos subalternizados em diferentes ordens: no caso deste estudo, são meninas pobres numa lógica machista, adultocêntrica e profundamente desigual.

Ana Carolina é protagonista da terceira e última história de vida a qual recorremos nesta narrativa. O primeiro registro sobre ela nos prontuários da rede de assistência social de Florianópolis é um documento do Instituto Médico Legal. Então com sete anos, fora espancada pela mulher com quem habitava. Ana Carolina a entendia como sua mãe. O motivo da violência: ela e os irmãos comeram todos os pãezinhos. No entanto, apenas Ana Carolina fora vítima de agressão, tendo sido encaminhada para abrigamento temporário. O ano era 1997. Com relação à mãe, observamos tratar-se de uma tia paterna, a quem Ana Carolina fora "dada" a criar, ainda bebê. O pai, que viera a conhecer anos mais tarde, era alcoólatra e morador de rua na região oeste de Santa Catarina. Não há registro sobre sua mãe biológica.

No ano de 2001, quando a trajetória de Ana Carolina volta a cruzar-se com a dos programas sociais, a menina afirma estar viciada em crack. Seu abrigamento é viabilizado quando, expulsa do lar, é encontrada perambulando pelas ruas. Uma vez abrigada, conforme seu relato, recebeu o convite de uma companheira para se prostituir. Segundo contou aos assistentes sociais, três homens "apareceram" em um momento em que ela estava desacompanhada e, temerosa, desistiu de "fazer programa", mas os referidos homens a violentaram sexualmente. De retorno à Casa de Passagem - assim chamado um abrigo temporário existente na cidade - seu comportamento é descrito como depressivo. Os prontuários não informam se Ana Carolina recebeu os devidos cuidados psicológicos decorrentes deste diagnóstico. 
Quando contava com 11 anos completos, Ana Carolina foi encaminhada para viver em um lar adotivo. Conforme se observa nos prontuários, seu comportamento fora apontado como motivação para que o casal adotante, conhecido da tia paterna com a qual coabitara anteriormente, alegasse incompatibilidade familiar. Após uma série de denúncias de maus tratos e violências físicas, a família “devolveu” Ana Carolina junto à Vara da Infância e da Juventude de Florianópolis. Como não podia seguir com a família que, além de maltratá-la, não a queria mais, a menina teve novamente o seu abrigamento em Casa Lar determinado pelo juizado competente.

Um ano mais tarde, observamos através dos relatórios que a situação de violação dos direitos de Ana Carolina se agravou. A então adolescente havia residido temporariamente, entre 2001 e 2003, com quase uma dezena de namorados e vivia de "favores de amigos não muito recomendados" 23 , segundo relatado pelos/as assistentes sociais. Sua situação oscilou entre períodos de abrigamento e de residência incerta. Mantivera relações sexuais com abrigados do Núcleo de Atenção Psicossocial, construção contígua à Casa Lar onde residia, e fora encontrada prostituindo-se nas proximidades da Praça XV de Novembro, no centro de Florianópolis. A quantidade de Boletins de Ocorrência realizados contra a adolescente, além de advertências judiciais e relatos das tensões com a parentela sugere que a rede de promoção social tivera muitas dificuldades em definir que encaminhamentos tomar para com Ana Carolina. Um diagnóstico-síntese de suas fugas afirma o seguinte: "Perfis das violências sofridas: estupros confirmados, beliscões e socos com marcas confirmados" 24 .

Em 2004, os horizontes da vida de Ana Carolina iriam se alterar. Até este momento, os inúmeros atos infracionais cometidos e a impossibilidade de manter vínculos e/ou residência fixa junto à parentela parece haver desaconselhado a escola ou o trabalho como medidas de integração social. O caso apresenta-se "de alta complexidade". Incapazes de atender as demandas da adolescente, que se vale da Casa de Passagem para alimentar-se e fazer a higiene, evadindo-se em seguida rumo aos "programas", já uma prática costumeira, o psiquiatra que a assistia definiu a situação de Ana Carolina da seguinte maneira:

foram várias as situações que demonstraram seus aspectos antissociais (...). No entanto, sabemos que muito já é parte de sua personalidade, não havendo outra alternativa a não ser oferecer-lhe um ambiente sadio, acolhedor e disciplinado. Este é o único tratamento para Ana Carolina ${ }^{25}$.

Inabilitado o seu acolhimento em "ambiente sadio, acolhedor e disciplinado", os/as profissionais pareciam enxergar a maternidade, já então inevitável, como a possibilidade para 
um recomeço. Ana Carolina engravidara de um namorado e, devido à tríade com que era comumente descrita - prostituição, consumo e tráfico de drogas - foi encaminhada à tratamento terapêutico em regime fechado de internação. A adolescente, aos 14 anos de idade, aceitou a medida privativa de liberdade que lhe fora atribuída, permanecendo quatro meses internada e um ano, conforme descreveu, "limpa", ou seja, sem utilizar entorpecentes.

A história de Ana Carolina no Programa Social Sentinela se inicia de maneira distinta daquela observada no caso das meninas Valentina e Mariana. Enquanto estas duas, uma vez incorporadas ao programa por abuso e violência sexual passaram a exercer atividades sexuais comerciais ao longo do atendimento, Ana Carolina tem seu prontuário iniciado dadas as fugas para conseguir os "programas". Ou seja, ela se insere definitivamente e se manterá ligada à rede de assistência social de Florianópolis até a maioridade por exploração sexual comercial. Já no caso de Mariana, apesar dos prontuários não se referirem à prática da prostituição, os/as assistentes sociais indicaram este caso como se caracterizando por exploração sexual consequente ao abuso sofrido ${ }^{26}$.

Uma vez inseridas no mesmo programa social e tendo sido assistidas durante período semelhante, torna-se imprescindível o questionamento acerca das resolutivas que decidiram sobre as vidas de nossas três protagonistas, as quais foram sensivelmente diferenciadas. Como se procurou demonstrar, no caso de Valentina predominou um atendimento de perspectiva familista: os profissionais consideraram que, embora o agressor coabitasse o mesmo espaço doméstico, a ligação da menina com a mãe e a avó não deveria ser desfeita. Ainda que Valentina tenha exercido práticas sexuais comerciais, cujo exemplo era tomado da mãe e da avó, os/as profissionais da rede de proteção e assistência à infância e à juventude de Florianópolis não consideraram esse fator determinante para o afastamento entre a menina e sua família. Conforme observou-se na narrativa de seus relatórios situacionais, o atendimento visou "minorar os riscos" aos quais Valentina estava submetida. Isto significou, na prática, acompanha-la esporadicamente, através de ligações telefônicas e visitas domiciliares; atentar e buscar atender as suas demandas socioeconômicas; e encaminhá-la ao universo laboral como forma alternativa à exploração sexual para o recebimento de valores econômicos.

Os casos de Mariana e Ana Carolina foram considerados mais complexos por aqueles/as que os acompanharam. Mariana fora vítima de abuso sexual perpetrado pelo pai biológico. $\mathrm{O}$ juiz da Vara da Infância e da Juventude considerou a separação entre ambos irreversível: o genitor não voltou a ver a filha até o momento em que seu caso deixou de ser acompanhado, quatro anos após a denúncia e o imediato abrigamento de Mariana. Com a violência sofrida, 
Mariana parece ter sido novamente vitimada com a sua separação da mãe e dos irmãos, uma vez que ela, ao invés do agressor, fora afastada da convivência familiar e comunitária.

Devido ao diagnóstico de negligência parental, toda a prole do casal, com exceção de Paulinho, foi encaminhada à adoção. Acreditamos que Paulinho tenha sido exceção devido à idade avançada. Dentre aqueles que foram abrigados, Mariana foi a única que não encontrou um lar adotivo, pois tinha à época 11 anos de idade, enquanto seus irmãos eram ainda crianças pequenas. Consideramos que a atuação da rede de promoção social no caso de Mariana cometeu negligências em relação aos preceitos do Estatuto da Criança e do Adolescente, uma vez que se operou a lógica família versus abrigamento, sem que outras possibilidades fossem aventadas por exemplo, a manutenção de vínculos com outros membros da família, ou um trabalho psicossocial sistemático e de promoção social com a genitora. Se este ocorreu, os prontuários não o abarcaram. Uma vez inserida no Programa Social Sentinela, este não zelou pelo seu direito à convivência familiar e comunitária, primeiro, quando optou por apartá-la do lar materno, e depois, quando permitiu a desconstrução dos vínculos entre a menina e seus irmãos.

Dentre os casos narrados, o único cujo desfecho pôde ser observado foi o de Ana Carolina. Uma vez procurado o programa, após completar a maioridade, a jovem obteve o seguinte parecer:

(...) entramos em contato e fomos informados que a decisão do Conselho Tutelar é não fazer nada, já que Ana Carolina tem 18 anos. (...) Não mais se encaixando no Programa Sentinela, foi encaminhada para [o] Abordagem de Rua, que não é tão "atencioso", no sentido de dar total assistência, mas prevê qualquer atenção e ajuda a pessoas em situação de rua ${ }^{27}$.

Ana Carolina foi caso único, também, pois teve seu abrigamento permanente solicitado diversas vezes por um psiquiatra que se envolvera fraternalmente com a adolescente, tendo-a acompanhado durante anos. Apesar de comprovada a incapacidade dos regimes abertos - como o das Casas Lar e o da Casa de Passagem - ou das clínicas terapêuticas em reverter definitivamente o quadro de privações e violências que vivenciou, não havia maneira de impedir as fugas, que resultavam reincidentemente na prática de atividades sexuais comerciais para fins, sobretudo, da manutenção do vício em crack. A impossibilidade de inserir Ana Carolina em uma família, já nos últimos anos de acompanhamento, foi considerada nula devido ao seu histórico intempestivo e ao vício em entorpecentes. Por outro lado, os regimes de privação de liberdade destinavam-se, exclusivamente, aos adolescentes reincidentes no conflito com a lei, não havendo no Estado de Santa Catarina instituições terapêuticas de coabitação permanente 
para casos como o da adolescente. Este quadro, visivelmente de difícil resolução, foi responsável pela destituição do poder familiar de Henrique, o bebê que Ana Carolina deu à luz em 2004. Henrique foi adotado um ano depois do seu nascimento e Ana Carolina não mais voltou a vê-lo, sendo tema de grande emoção para a jovem.

\section{Considerações finais}

No período compreendido entre 1990 e 2010 estavam sendo assistidos por exploração sexual comercial no município de Florianópolis sujeitos definidos em termos de gênero, classe social e raça/etnia. Os prontuários estudados durante a investigação, dos quais se extraiu os três aqui analisados, são de meninas pobres, que habitavam os morros do centro da capital de Santa Catarina; marcadas por vínculos familiares frágeis; identificadas como negras ou "pardas"; e que possuíam certa liberdade e independência para ir e vir entre espaços da urbe. As violências ocorriam sobretudo dentro de casa, como nos casos de Valentina e Mariana, ou sob a tutela do Estado, a exemplo do que ocorreu com Ana Carolina. As meninas possuíam entre nove e 11 anos quando da perpetração das primeiras violências.

Utilizando um conjunto de conceitos mobilizados à época para analisar as medidas de acompanhamento do Programa Social Sentinela, observamos que Valentina fora vítima de atos libidinosos que se caracterizam como abuso sexual. Uma vez que o perpetrador da violência foi o avô materno, sua situação envolve uma relação incestuosa de segundo grau. Anos mais tarde a conjuntura do atendimento permitiu atentar que a menina havia se envolvido em práticas de exploração sexual comercial, além de violências sexuais perpetradas pelo padrasto. Sabe-se pouco em relação a estas violências, pois os prontuários apenas as enunciam. Mariana foi vítima de violência sexual perpetrada pelo pai, caracterizando-se situação/violência mais grave: uma "classe" de incesto que gerou maiores preocupações de parte da rede de assistência social do município de Florianópolis. A caracterização do caso de Ana Carolina, por sua vez, iniciou com o diagnóstico de exploração sexual comercial. Sua condição de vulnerabilidade, no entanto, "progrediu" para situações combinadas de violências, físicas e sexuais, além de exploração sexual comercial.

Caracterizar o perfil das violências atendidas pelo Programa Social Sentinela permitiu compreender a dinâmica do atendimento e as metodologias de enfrentamento elencadas pela rede protetiva e assistencial. O programa trabalhou em duas frentes, no que diz respeito aos casos em questão: um frágil empoderamento familiar para lidar com as violências sofridas e o 
abrigamento, quando se evidenciou a impossibilidade do convívio familiar. Mariana fora caso tipificado como pertencente a uma família incapaz de promover o seu desenvolvimento. Com relação à genitora, a rede protetiva entendeu que ela havia sido conivente com o abuso sexual sofrido pela menina, uma vez que permitiu o retorno do pai/abusador ao lar. A negligência para com os demais filhos do casal, com a verificada situação de abandono, mendicância e evasão escolar foi o estopim para o desligamento permanente entre os genitores e a prole. Se o comportamento familiar em relação aos irmãos de Mariana tivesse sido satisfatório, talvez o programa tivesse se esforçado em trabalhar o tema do abuso com cada um dos seus membros. Isto, no entanto, não ocorreu. A única referência a um trabalho social fora o realizado com a mãe de Mariana, de forma descontinuada, que culminou no diagnóstico de "negligência parental". O pai, além da prisão temporária, fora proibido de aproximar-se da menina. Nenhuma tentativa de trabalhar as violências foi realizada com ele. Impossibilitada de retornar ao lar e "passada" em termos etários para a adoção, Mariana possivelmente permaneceu abrigada até completar a maioridade. Desconhecemos se logrou manter algum vínculo familiar.

A impossibilidade de convivência familiar não foi decretada para o caso de Valentina. Talvez seus abusadores - avô materno e padrasto - não coabitassem de maneira permanente a mesma residência. Na documentação analisada não há informações sobre uma possível medida cautelar, protetiva para Valentina em relação ao avô, como no caso de Mariana. Sobre o padrasto, sabemos que retomou a relação com a mãe da menina, após algum tempo. $\mathrm{O}$ abrigamento temporário da adolescente deu-se por razões ligadas à considerada incapacidade materna em administrar suas atividades laborais e o cuidado da filha. A genitora não chegou a ter suspenso o poder familiar, tampouco entendemos que a rede de proteção social centrou o atendimento no abuso e violências sofridas, dedicando-se a coibir as atividades sexuais comerciais da adolescente, ao tratar de "ocupá-la" em outras atividades laborais.

O caso de Ana Carolina, talvez mais do que os demais, aponta a necessidade de se questionar o alcance do atendimento psicossocial dos programas sociais brasileiros, no momento histórico analisado. Operando a lógica do empoderamento familiar e de abrigamentos temporários, o programa apresentou-se ineficaz em relação às vivências da menina que não se enquadravam nessas resoluções. A assim chamada perspectiva familista, pela qual se pauta 0 trabalho social pós-1988, é fruto da tentativa de erradicar a separação da criança e do adolescente do convívio familiar por questões socioeconômicas ou culturais, demonstrando o esforço do Estado brasileiro em respeitar as diversas dinâmicas familiares mediante o fortalecimento das relações. Em suma, a lógica dos direitos converge para a manutenção do 
sujeito na família. Mas, se verificada a incapacidade familiar, sua falta de interesse na promoção das infâncias e juventudes a seu cargo e, em casos extremos, a inexistência de vínculos afetivos significativos entre a criança e a parentela de origem, e que essas violências socioemocionais resultem em expressões que obstaculizem sua inserção sob tutela ou adoção, quais alternativas cabem às nossas infâncias e juventudes? Nos casos de Mariana e Ana Carolina, as políticas de atendimento não permitiram a resolução de seus conflitos, dentre outras coisas, porque as metodologias de atendimento, uma vez subtraídas as famílias de origem, demonstraram-se lacunares e insuficientes; numa palavra, resultaram no seu abrigamento cautelar, que se fez permanente.

Trabalhando com metodologias de atendimento em construção no que se refere à exploração sexual comercial, nas duas primeiras décadas de vigência do Estatuto da Criança e do Adolescente, a rede de proteção e assistência social de Florianópolis compreendia a condição peculiar de sua demanda - meninas pobres, emocionalmente vulneráveis e sexualmente violentadas. Atentando às histórias de vida de Valentina, Mariana e Ana Carolina, no entanto, não observamos a implantação de medidas socioassistenciais para além de um atendimento contingencial: as meninas entendiam o Programa Social Sentinela como fonte de cuidados aleatórios, tais como receber alimento, banhar-se, dormir com segurança ou realizar uma consulta médica. A atuação do referido Programa nas trajetórias dessas meninas garantiu a sua sobrevivência, se apresentando como agente de "redução de riscos" e cuidados emergenciais, mas não logrou - em que pese nosso desconhecimento dos desfechos de suas histórias - a superação das violências sofridas, sua promoção ou o gozo pleno dos seus direitos.

\section{Referências bibliográficas}

AREND, Silvia Maria Fávero. Rompendo o silêncio: violências sexuais, infâncias e direitos (1989-2000). Revista Outros Tempos, v. 17, n. 29, p. 205-220. 2020. Disponível em: https://www.outrostempos.uema.br/OJS/index.php/outros_tempos_uema/article/view/762/pdf. Acesso em: abr. 2020.

BRASIL. Código de Menores de 1927. Decreto n. 17.943 A, de 12 de outubro de 1927.

BRASIL. Código de Menores de 1979. Lei n. 6.697, de 12 de outubro de 1979.

BRASIL. Estatuto da Criança e do Adolescente. Lei n. 8.069, de 13 de julho de 1990.

COUTINHO, Mariana Garcez. Papéis e vidas: crianças e adolescentes vítimas de violência que aguardam em fila de espera - um estudo no Serviço Sentinela de Florianópolis. Trabalho de Conclusão de Curso (Graduação em Assistência Social). Universidade Federal de Santa Catarina, 2008. 
DEBASTIANI, Cinara; BELLINI, Maria Isabel Barros. Fortalecimento da rede e Empoderamento Familiar. Revista Boletim de Saúde, Porto Alegre, v. 21, n. 1, jan./jun. 2007, pp. 77-87. Disponível em:

https://repositorio.pucrs.br/dspace/bitstream/10923/8188/2/Fortalecimento_da_Rede_e_Empo deramento_Familiar.pdf. Acesso em: nov. 2021.

DAMINELLI, Camila Serafim. Anjos Caídos: um estudo sobre exploração sexual comercial feminina em Florianópolis (1990-2008). Trabalho de Conclusão de Curso (Graduação em História). Universidade do Estado de Santa Catarina, 2010.

FALEIROS, Eva T. Silveira. Repensando os conceitos de violência, abuso e exploração sexual de crianças e adolescentes. Brasília: Thesaurus, 2000.

HIRATA, Helena. Gênero, classe e raça: interseccionalidade e consubstancialidade das relações sociais. Revista Tempo Social, v. 26, n. 1, p. 61-73, jun. 2014. Disponível em: http://www.revistas.usp.br/ts/article/view/84979/87743. Acesso em: mai. 2020.

IBGE. Sinopse do Censo Demográfico 2000. Disponível em:

https://censo2010.ibge.gov.br/sinopse/index.php?dados=6. Acesso em: mai. 2020.

LIBÓRIO, Renata Maria Coimbra. Adolescentes em situação de prostituição: uma análise sobre a exploração sexual comercial na sociedade contemporânea. Psicologia Reflexão e Crítica, v. 18, n. 3, p. 413-420, dez. 2005). Disponível em:

https://www.scielo.br/scielo.php?pid=S0102-

79722005000300016\&script=sci_abstract\&tlng=pt. Acesso em: set. 2017.

MOTTA, Márcia Maria Menendes. História, memória e tempo presente. In: CARDOSO, Ciro Flamarion; VAINFAS, Ronaldo. (Orgs.). Novos domínios da História. Rio de Janeiro: Elsevier, 2012. pp. 21-36.

NOGUEIRA, Maria Luísa Magalhães; BARROS, Vanessa Andrade de; ARAUJO, Adriana Dias Gomide; PIMENTA, Denise Aparecida Oliveira. O método de história de vida: a exigência de um encontro em tempos de aceleração. Pesquisas e Práticas Psicossociais, v. 12, n. 2, p. 466-485, mai./ago. 2017. Disponível em:

http://pepsic.bvsalud.org/pdf/ppp/v12n2/16.pdf. Acesso em: mai. 2020.

SEGUNDO, Rinaldo. Notas sobre o direito da criança. Jus Navegandi, n. 61, s/p., jan. 2003. Disponível em: https://jus.com.br/artigos/3626/notas-sobre-o-direito-da-crianca/3. Acesso em: jul. 2016.

SCOTTI, Zelinda Rosa. Os prontuários do Hospício São Pedro: metodologia para formação de banco de dados. Revista Ágora, n. 12, p. 1-12, 2010. Disponível em:

https://periodicos.ufes.br/agora/article/view/1967/1479. Acesso em: ago. 2016.

SUDBRACK, Umberto Guaspari. O extermínio de meninos de rua no Brasil. São Paulo em Perspectiva, v. 18, n. 1, p. 22-30, jan./mar. 2004. Disponível em: https://www.scielo.br/scielo.php?script=sci_arttext\&pid=S0102$88392004000100004 \& \operatorname{lng}=\mathrm{en} \& n r m=$ iso\&tlng=pt. Acesso em: mai. 2020. 
VENÂNCIO, Ana Teresa; CASSILLAS, Janis Alessandra. A doença mental como tema: uma análise dos estudos no Brasil. Revista Espaço Plural, v. 12, n. 22, p. 24-34, jan./jun. 2010. Disponível em: http://e-revista.unioeste.br/index.php/espacoplural/article/view/4831/3699. Acesso em: ago. 2016.

Recebido em 15/09/2021. Aceito em 08/11/2021.

\footnotetext{
${ }^{1}$ Todos os nomes utilizados neste estudo são fictícios. A única referência fidedigna aos casos encontra-se nos números dos prontuários de atendimento.

${ }^{2} \mathrm{O}$ estudo da documentação do Programa Social Sentinela faz parte do projeto de pesquisa "Relações de trabalho infantojuvenis no Brasil: experiências femininas e masculinas no mundo urbano", já finalizado, vinculado ao Laboratório de Relações de Gênero e Família da Universidade do Estado de Santa Catarina, sob a coordenação da Profa. Dra. Silvia Maria Fávero Arend. O recorte temporal do estudo abarca os vinte primeiros anos de vigência do Estatuto da Criança e do Adolescente, sancionado no Brasil em 13 de julho de 1990.

${ }^{3}$ Prontuário de atendimento n. 36. Programa Social Sentinela, Prefeitura Municipal de Florianópolis.

${ }^{4}$ O Conselho Tutelar, conforme definição estatuária, é um órgão permanente e autônomo, não jurisdicional, encarregado de zelar pelo cumprimento dos direitos das crianças e dos adolescentes brasileiros. Como todos os órgãos que executam as políticas de assistência e proteção infantojuvenil, atua em âmbito municipal. Seus membros são elegidos a cada quatro anos pelo voto universal. Dispõe sobre o Conselho Tutelar o Art. 131 do Estatuto da Criança e do Adolescente. Ver: BRASIL (1990).

${ }^{5}$ Prontuário de atendimento n. 36. Programa Social Sentinela, Prefeitura Municipal de Florianópolis.

${ }^{6}$ Boletim de Ocorrência (BO) consiste em um documento com validade em todo o território nacional, utilizado pelas forças policiais para fazer o registro da ocorrência de um crime. No âmbito do Sistema de Garantia de Direitos infantojuvenil, trata-se do primeiro encaminhamento realizado no sentido de formalizar a ocorrência de um crime que envolva crianças e adolescentes, para a apuração via inquérito, sob responsabilidade das Varas da Infância e Juventude dos municípios ou comarcas do Brasil.

${ }^{7}$ Florianópolis, capital do Estado de Santa Catarina, contava no ano de 1991 com cerca de 255 mil habitantes, de acordo com dados do Censo Demográfico do ano 2000. Em termos geoespaciais, o município está composto por uma parte insular e pela Ilha de Santa Catarina, onde se situa o centro da cidade. Ver: IBGE, 2000.

${ }^{8}$ De acordo com o título II, Seção II do Estatuto da Criança e do Adolescente, os procedimentos de suspensão ou destituição do poder familiar terão início por provocação do Ministério Público ou por quem de legítimo interesse - o Conselho Tutelar, por exemplo. Havendo denúncia grave, a suspensão do poder familiar poderá ser expedida em até cinco dias. Considera-se a gravidade da situação tendo em vista os direitos fundamentais da criança e do/a jovem como sujeito em desenvolvimento, dispostos no Art. $5^{\circ}$ : negligência, exploração, violência, crueldade e opressão, por ação ou omissão da família, que venha a inferir no seu desenvolvimento físico, mental, moral ou social, em condições de dignidade (BRASIL, 1990).

${ }^{9}$ Prontuário de atendimento n. 36. Programa Social Sentinela, Prefeitura Municipal de Florianópolis.

10 As meninas constituem a quase totalidade da demanda do referido programa social. Além disso, os encaminhamentos dos meninos são mais frágeis, descontinuados, razão pela qual optamos por focar a investigação nos prontuários de meninas atendidas pelo Sentinela.

11 Todos estes, cabe dizer, são programas que operam atendimento e encaminhamento específicos para demandas já definidas, havendo procedimentos de acolhimento e triagem que lhes são anteriores.

${ }^{12}$ Para uma análise dos debates internacionais acerca da temática das violências e da exploração sexual comercial, bem como de sua incorporação às normativas jurídicas brasileiras, ver: AREND, 2020.

${ }^{13}$ Grupos paramilitares, formados por policiais, ex-policiais e agentes de segurança privada, que se organizaram com a finalidade de executar determinados grupos sociais, tais como indígenas, negros e meninos e meninas de rua, estes últimos sobretudo no período entre 1985-1995. Os "serviços" eram encomendados por comerciantes e outros setores da sociedade civil, visando uma propalada "higienização social". Para esta discussão, ver: SUDBRACK, 2004.

14 Atualmente, após a promulgação da Lei 12.015, de 07 de agosto de 2009, que altera o Capítulo II do Código Penal de 1940 relativo aos crimes sexuais contra vulnerável, a idade corte é de 14 anos.

15 É importante observar que, em relação ao público adulto, o termo estupro permanece sendo utilizado para nomear o que na legislação brasileira configura crime hediondo: prática sexual, com ou sem uso da força, sem consentimento. Para o público infantojuvenil, embora no âmbito do Direito Penal e, sobretudo, no jargão jurídico,
} 
Fronteiras - Revista Catarinense de História | https://periodicos.uffs.edu.br/index.php/FRCH/index

ISSN 2238-9717 | n. 38, p. 102-122, jul.-dez./2021 | DOI: https://doi.org/10.29327/253484.1.38-7

convivam com a concepção de violência sexual termos como "corrupção de menores", "conjunção carnal" e “estupro de vulnerável”, a noção de violências, no plural, já se fazia presente no período estudado. A acepção abarcava também os assim chamados "atos libidinosos", com a ausência de relação sexual propriamente dita, mas que configuravam igualmente uma violência sofrida.

${ }^{16}$ Prontuário de atendimento n. 141. Programa Social Sentinela, Prefeitura Municipal de Florianópolis.

17 Idem.

${ }^{18}$ No acompanhamento dos casos as/os assistentes sociais registram diariamente contatos telefônicos, encontros e encaminhamentos, posteriormente sintetizados em Relatórios Sociais enviados ao Juizado da Infância e da Juventude.

${ }^{19}$ Prontuário de atendimento n. 141. Programa Social Sentinela, Prefeitura Municipal de Florianópolis.

${ }^{20}$ Idem.

${ }^{21} \mathrm{Um} / \mathrm{a}$ assistente social relatou que em uma das fugas da instituição onde estivera abrigada, Mariana se encontrou com um adolescente, que a convidou para comer uma pizza em sua casa, para onde se encaminharam. No local, tiveram relações sexuais não violentas, de acordo com o relato de Mariana. Prontuário de atendimento n. 141. Programa Social Sentinela, Prefeitura Municipal de Florianópolis.

${ }^{22}$ Prontuário de atendimento n. 141. Programa Social Sentinela, Prefeitura Municipal de Florianópolis.

${ }^{23}$ Prontuário de atendimento n. 42. Programa Social Sentinela, Prefeitura Municipal de Florianópolis.

${ }^{24}$ Idem.

${ }^{25}$ Idem.

${ }^{26}$ Cabe uma explicação: quando da realização da pesquisa, oa/as assistentes sociais indicaram cinco meninas com histórico de exploração sexual comercial para que começássemos o estudo pelos seus prontuários. Em seguida, foram realizadas entrevistas orais com estas cinco adolescentes. No entanto, no que cabe a esta narrativa, optouse por analisar apenas três dos prontuários estudados, e por não utilizar as narrativas orais, uma vez que implicariam outros debates teórico-metodológicos.

${ }^{27}$ Prontuário de atendimento n. 42. Programa Social Sentinela, Prefeitura Municipal de Florianópolis.

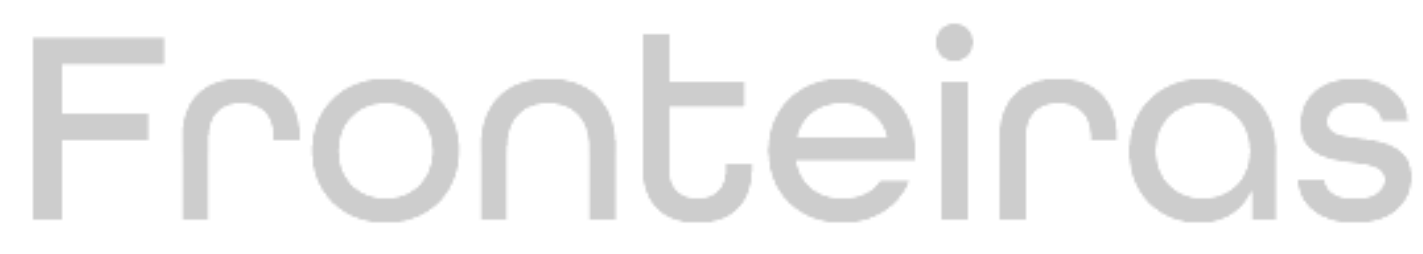

